\title{
First-time admissions for opioid treatment: cross- sectional and descriptive study of new opioid users seeking treatment
}

This article was published in the following Dove Press journal:

Neuropsychiatric Disease and Treatment

24 September 2015

Number of times this article has been viewed

Gerardo Flórez, ${ }^{1,2}$ Ana López-

Durán, ${ }^{3}$ Yolanda Triñanes, ${ }^{4}$ Jesús Osorio, ${ }^{5}$ Jaime Fraga, ${ }^{5}$ José Manuel Fernández, ${ }^{5}$ Elisardo Becoña, ${ }^{3}$ Manuel Arrojo ${ }^{5}$

'Addictive Disorders Assistance Unit, Complejo Hospitalario, Ourense, Spain; ${ }^{2}$ Center for Biomedical Research in Mental Health (CIBERSAM), Oviedo, Spain; ${ }^{3}$ Department of Clinical Psychology and Psychobiology, University of Santiago de Compostela, Spain; ${ }^{4} \mathrm{G}$ alician Agency for Health Technology Assessment, Directorate General for Innovation and Management of Public Health, Galicia, Spain; ${ }^{5}$ Directorate General of Health Assistance, Galician Health Service, Galicia, Spain

\section{Video abstract}

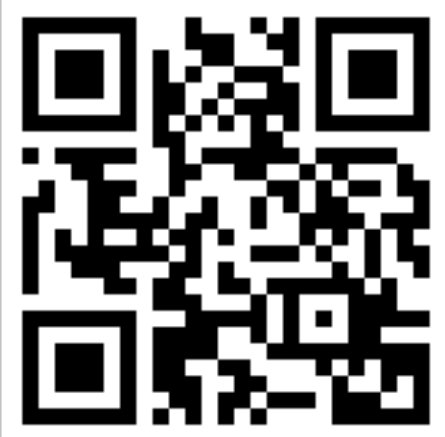

Point your SmartPhone at the code above. If you have a QR code reader the video abstract will appear. Or use

http://youtu.be/YwnMirLY6Ic

Correspondence: Gerardo Flórez Complejo Hospitalario de Ourense, Ramón Puga 52-56, 32005 Ourense, Spain

$\mathrm{Tel}+34988369838$

Fax +34988385482

Email gerardof@mundo-r.com
Background: The purpose of this study was to gain an understanding of the profiles of the new treatment demands posed by opioid addicts between 2005 and 2010 at the addictive disorders assistance units in Galicia, Spain.

Methods: A cluster analysis was performed using data from 1,655 treatment entrants. Clusters were constructed using sociodemographic and medicolegal variables. A cluster analysis was also conducted according to age. Once clusters were defined, their association with the following variables was analyzed: age at first use of opioids, years of use, frequency of opioid use in the previous month, psychiatric treatment, cocaine use, existence of a drug-dependent partner, and source of referral.

Results: Four clusters were obtained in the main analysis. Cluster $1(34.01 \%)$ consisted of young males, cluster $2(16.19 \%)$ consisted of not-so-young males, cluster $3(32.62 \%)$ consisted mainly of older males and a small group of females, and cluster $4(17.18 \%)$ was made up entirely of women. With regard to age-related clusters, two clusters were obtained in those under the age of 30 years: cluster $1(73 \%)$ without medicolegal complications and cluster 2 $(27 \%)$ with medicolegal complications. For those over the age of 30 years, two clusters were obtained: cluster $1(53.92 \%)$ with hardly any medicolegal complications and cluster $2(46.08 \%)$ with medicolegal complications.

Conclusion: Cluster analysis suggests that there have been no substantial changes in variables indicating greater severity in this new group of patients. Women are likely to seek help earlier, which reduces their duration of opioid use. The younger the patient, the shorter the duration of opioid use and the greater the likelihood of cessation of intravenous use. Public health systems should use a two-pronged treatment strategy of short but intense cessation therapies for women and younger treatment entrants and longer maintenance and replacement therapies for older treatment entrants with more psychosocial and medical complications.

Keywords: opioid dependence, cluster analysis, treatment-seeking, sex, age

\section{Introduction}

Addiction to opioids is a chronic condition with severe repercussions in the health domain (early death, transmission of infectious diseases) and psychosocial domain (legal, family, social, and occupational problems). ${ }^{1,2}$

This serious public health issue has gone through different stages in Europe, including Spain in general and Galicia specifically, ie, the northwestern region of Spain where our study took place, ${ }^{3}$ from being a serious social and public health problem (particularly with regard to transmission of human immunodeficiency virus [HIV] and hepatitis $\mathrm{C}$ virus [HCV]) in the 1980s and 1990s, to later becoming a less prominent problem, ${ }^{3}$ although a recent meta-analysis ${ }^{4}$ places opioid dependency as the second 
leading mental disorder with the greatest risk of death behind only puerperal psychiatric disorder.

In Spain, according to data from a general survey of the adult population conducted in 1995, 0.8\% had tried heroin and $0.5 \%$ had done so in the previous 12 months, while in 2011 the corresponding figures were $0.6 \%$ and $0.1 \% .^{5}$ This decrease is reflected in the clinical setting, with a reduction in admissions for treatment of opioid abuse of $93.1 \%$ in 1995 to $36.9 \%$ in 2011 (over the total of substance abuse admissions) at the specialized units in Galicia, with no changes in the treatment system during that period. ${ }^{6}$ This decrease has also been reported in the European Union, ${ }^{3}$ which has experienced a decrease from 59,000 in 2007 to 31,000 in 2012. The same report indicates that, in Spain, the prevalence of problem opioid use was less than 2.5 per 1,000 in $2011 .^{3}$

Of particular interest is whether these changes are a mere reduction in numbers or whether there have been changes in the profile of patients seeking treatment in more recent years. Recently, profile analyses have been conducted regarding the use of tobacco, ${ }^{7,8}$ alcohol, ${ }^{9}$ and cocaine, ${ }^{10}$ but there has been less research concentrating on heroin users. There is indeed evidence of a high prevalence of dual disorders in opioid users. ${ }^{11,12}$ For instance, the COPSIAD study, ${ }^{13}$ also conducted in Galicia, reported a high prevalence of personality disorders (26.5\%), mood disorders (20.6\%), anxiety disorders (11.9\%), and psychotic disorders (7.6\%) in 805 persons who sought treatment for heroin use at specialized units.

The following variables have been identified to have an influence on the level of disability in opioid-addicted patients: age, with a greater probability of polyconsumption of addictive substances amongst younger populations; ${ }^{14}$ sex, with females showing a lower incidence of opioid addiction, more psychiatric disorders, ${ }^{15}$ more chronic health problems, and lower levels of social and occupational functioning, ${ }^{16}$ their partners having a greater influence on initiation of use, and females also more frequently practicing prostitution and sharing injecting paraphernalia; ${ }^{17}$ psychiatric comorbidity, with figures ranging between $44 \%$ and $93 \%$ of persons seeking treatment; ${ }^{12,18}$ infectious diseases, with a 25-year longitudinal clinical study conducted in Spain reporting that $47.2 \%$ of a sample was also diagnosed with HIV and $81.1 \%$ with hepatitis $\mathrm{B} / \mathrm{HCV} ; ;^{18,19}$ and legal problems, which are associated with greater severity of addiction, and, in some clinical samples, even survival at 12 months..$^{19,20}$

These variables determine a variety of user profiles that have an influence on preventive and therapeutic decision making. ${ }^{21,22}$ For instance, patients with less severe profiles (fewer physical and psychiatric comorbidities, less polysubstance abuse, fewer incarcerations) will benefit from shorter programs while those with more severe profiles will benefit from long-term maintenance programs. ${ }^{23}$ Females would require more exhaustive assessment because they have a higher risk of a more severe profile and, as a result, may need more intensive and individualized treatments. ${ }^{24}$

The aim of this study was to gain an understanding of the profile of those who started treatment for opioid addiction for the first time between 2005 and 2010 at the addictive disorders assistance units in Galicia. Our a priori hypothesis was that variables with historically defined severity profiles will continue to exist for new treatment entrants.

\section{Materials and methods}

This was a cross-sectional and descriptive study of opioiddependent patients starting treatment at the addictive disorders assistance units of Galicia in the northwestern region of Spain, which has a population of 2,797,653. The service comprises 17 drug dependency units and six alcoholism units, as part of the assistance provided by the free public health system. The service offers opioid substitution and drug-free treatment in inpatient and outpatient settings, all of which offer psychosocial rehabilitation.

\section{Sample}

The study included all patients who started treatment for the first time in their lives between 2005 and 2010 and who had an opioid as their main substance of abuse $(n=1,800)$. Of these, 145 were excluded because they could not provide data for any of the variables selected for the study. Therefore, the final sample consisted of 1,655 patients.

\section{Procedure}

In Galicia, health care assistance has been registered since 1994 using a specific computer application of the Galician Health Service. This tool, based on the EuropASI, ${ }^{25}$ collects patient details as necessary to be able to provide health care services at each unit. Sociodemographic, clinical, treatment, legal, and abuse (main and secondary substances) variables are collected, as well as data on infectious diseases (in particular hepatitis and HIV).

The data collected on admission for treatment are sent to the Spanish Department for the National Plan on Drugs (Ministry of Health and Social Policy, Government of Spain) and are included on the treatment admission register for use of psychoactive substances.

The procedure used to obtain information in this study involved extracting data from each patient who fulfilled the 
following inclusion criteria: admission for treatment at any assistance unit in Galicia between 2005 and 2010 and an opioid being the main substance of abuse. Our definition of main substance of abuse was a substance that met the following conditions: the most frequently used, the one leading to treatment demand, and the one causing greatest disability. Eligibility criteria were: ability to understand and sign informed consent to start treatment; age 18-65 years; and a Diagnostic and Statistical Manual of Mental Disorders (DSM) diagnosis of opioid dependence, ie, an opioid being the main substance of abuse.

\section{Ethics statement}

This study was approved by the ethics committee for clinical research in Galicia (2014-117). All the research was conducted according to the principles expressed in the Declaration of Helsinki. Participants provided their written informed consent to have their medical data used for research in all cases. Research was not conducted outside of country of residence.

\section{Statistical analysis}

An important decision in performing a cluster analysis is the selection of a set of measures that will serve as the basis for the cluster.

\section{Analysis}

A public health investigative approach was chosen for selection of clustering variables that could reveal the heterogeneity of new opioid users. ${ }^{26}$ The choice was balanced between variables that have shown prognostic importance and variables that can be ascertained rapidly and reliably in a valid manner. Sociodemographic variables included sex, age, marital status (single/married/other), education (primary school/beyond primary school), and source of income (job/other). With regard to drug use variables, the variable parenteral route of administration was selected (yes/no). HIV/acquired immune deficiency syndrome (AIDS) (yes/no) and HCV (yes/no) status was confirmed by self-report and clinical data, and incarceration was the variable considered from a legal standpoint (yes/no). ${ }^{12,14-20}$

\section{Clustering technique}

Subtypes of opioid users who started treatment for the first time were identified by a cluster analysis in two phases using the Statistical Package for the Social Sciences for Windows version 19 software (IBM Corporation, Armonk, NY, USA). This statistical technique is an exploratory procedure for identifying natural groups in a set of data (categorical and continuous) that would not be possible to detect otherwise. The first stage in the two-step clustering involves assigning cases to "preclusters". In the second step, the preclusters are clustered using the hierarchical clustering algorithm. All analyses were performed using measurement of log-similarity (such as that required by analyses including continuous variables as well as categories). We used the Bayesian information criterion fit statistic to evaluate each solution's fit relative to the other cluster solution. For the Bayesian information criterion, smaller values suggest better fitting solutions. ${ }^{27,28}$

Once the clusters were obtained, they were compared on the basis of the following clinically relevant variables: three variables related to opioid use, ie, age at initiation of opioid use, years of use, and frequency of opioid use over the past month (daily/other); a further three variables related to comorbidity, ie, psychiatric treatment (yes/no), cocaine use (yes/no), and existence of a drug-addicted partner (yes/no); and the last one related to motivation for treatment and source of referral (health services/own initiative/other).

We used the Student's $t$-test and analysis of variance with Bonferroni correction to examine the differences between clusters in age at initiation of heroin use. Chi-square analyses with Bonferroni correction were carried out for the remaining variables. Differences were considered to be statistically significant at $P<0.05$ ( $P<0.025$ for the chi-square test with Bonferroni correction for two-level categorical variables and $P<0.015$ for three-level categorical variables).

\section{Results}

The mean age of the sample was $33.29 \pm 8.3$ years, $81.8 \%$ were male, $71.9 \%$ were single, and $58.5 \%$ had more than primary education. All baseline variables from the whole group are shown in Table 1.

\section{Cluster analysis}

Of the 1,655 study participants, 563 were classified in the first group (cluster 1), 268 in the second group (cluster 2), 540 in the third group (cluster 3), and 284 in the fourth group (cluster 4), as shown in Table 2.

With regard to demographic variables, subjects in clusters 1 and 4 were the youngest while those in cluster 2 had a higher mean age $\left(F_{(3,1651)}=90.64, P<0.001\right)$. Clusters 1 and 2 were composed entirely of males and cluster 4 entirely of females $\left(\chi_{(1)}^{2}=1,544.34, P<0.001\right)$. All subjects in cluster 1 were single, none in cluster 2 were single, while in clusters 3 and 4 they were more likely to be single $\left(\chi_{(1)}^{2}=925.63, P<0.001\right)$. Subjects in cluster 4 were more likely to have higher than 
Table I All baseline variables from the final sample

\begin{tabular}{|c|c|}
\hline Baseline variables & $M(S D)$ \\
\hline \multirow[t]{2}{*}{ Age, years } & $33.2(8.3)$ \\
\hline & n (\%) \\
\hline \multicolumn{2}{|l|}{ Sex } \\
\hline Male & I,354 (8I.8) \\
\hline Female & $30 I(18.2)$ \\
\hline \multicolumn{2}{|l|}{ Marital status } \\
\hline Single & I, 190 (7I.9) \\
\hline Married & $223(13.5)$ \\
\hline Other & $242(14.6)$ \\
\hline \multicolumn{2}{|l|}{ Education } \\
\hline Primary & $687(4 \mid .5)$ \\
\hline Beyond primary & $968(58.5)$ \\
\hline \multicolumn{2}{|l|}{ Source of income } \\
\hline Job & $650(39.3)$ \\
\hline Other & $\mathrm{I}, 005(60.7)$ \\
\hline Intravenous use (yes) & $258(15.6)$ \\
\hline HIVIAIDS (yes) & $123(7.4)$ \\
\hline Hepatitis C (yes) & $329(19.9)$ \\
\hline \multirow[t]{2}{*}{ Incarceration (yes) } & $446(26.9)$ \\
\hline & $M(S D)$ \\
\hline Age of initiation of use, years & $22.5(7.5)$ \\
\hline \multirow[t]{2}{*}{ Years of use } & $10.9(9.1)$ \\
\hline & n (\%) \\
\hline Psychiatric treatment (yes) & $402(24.3)$ \\
\hline Cocaine use (yes) & $829(50.1)$ \\
\hline Drug-dependent partner (yes) & $324(19.6)$ \\
\hline \multicolumn{2}{|l|}{ Source of referral } \\
\hline Health services & $315(19.0)$ \\
\hline Own initiative & $729(44.0)$ \\
\hline Other & $611(36.9)$ \\
\hline Frequency of use in the last month (daily) & $\mathrm{I}, 152(69.6)$ \\
\hline
\end{tabular}

Abbreviations: AIDS, acquired immune deficiency syndrome; HIV, human immunodeficiency virus; M, mean; SD, standard deviation.

primary education, while clusters 2 and 3 were more likely to have primary education only $\left(\chi_{(1)}^{2}=36.12, P<0.001\right)$. Subjects in clusters 1 and 2 were more likely to derive their income from work, while those in clusters 3 and 4 were more likely to earn income from other sources $\left(\chi_{(1)}^{2}=87.78, P<0.001\right)$.

With regard to method of drug administration, none of the subjects in clusters 1 and 2 had used the parenteral route, while those in cluster 3 were more likely to have used this route $\left(\chi_{(1)}^{2}=431.41, P<0.001\right)$. A higher proportion of subjects in cluster 3 were diagnosed with HIV/AIDS $\left(\chi_{(1)}^{2}=\right.$ 226.38, $P<0.001)$ and $\mathrm{HCV}\left(\chi_{(1)}^{2}=648.72, P<0.001\right)$ than in cluster 4 , with none in clusters 1 and 2 having these diseases. None of the subjects in cluster 1 had been incarcerated, whereas those in cluster 3 were more likely to have been in prison $\left(\chi_{(1)}^{2}=660.46, P<0.001\right)$.

\section{Relationship between the four clusters and other use-related variables}

Having defined the clusters, we analyzed their association with the following variables: age of initiation of opioid use, years of opioid use, frequency of opioid use in the previous month, psychiatric treatment, cocaine use, existence of a drug-addicted partner, and source of referral (Table 3).

Subjects in cluster 3 started to use opioids at a younger age, followed by clusters 1 and 4, and, lastly, those with the oldest age of initiation were in cluster $2\left(F_{(3,1651)}=43.23, P<0.001\right)$. Subjects in cluster 3 had been using opioids for longest, followed by subjects in cluster 2 and then cluster 1; those who had been using for the least number of years were women in cluster $4\left(F_{(3,1651)}=110.28, P<0.001\right)$. Subjects in cluster 4 were more likely to have received psychiatric treatment than those in cluster $2\left(\chi_{(1)}^{2}=36.46, P<0.001\right)$. Subjects in cluster 2 were less likely to have used cocaine $\left(\chi_{(1)}^{2}=18.11, P<0.001\right)$ and those in cluster 4 were more likely to have a drug-addicted $\operatorname{partner}\left(\chi_{(1)}^{2}=\right.$ $80.31, P<0.001)$. Subjects in cluster 3 were more likely than those in clusters 1 and 2 to have been referred from a health unit and less likely than those in clusters 1 and 2 to have sought treatment on their own initiative $\left(\chi_{(1)}^{2}=18.68, P<0.01\right)$. Subjects in cluster 3 were the least likely to have used opioids on a daily basis in the previous month $\left(\chi_{(1)}^{2}=55.24, P<0.001\right)$.

\section{Age-related cluster analysis}

Given the existing age differences, two further cluster analyses were performed. The first comprised subjects under the age of 30 years and the second comprised those aged 30 years or over. Of the 648 study participants younger than 30 years, 473 were classified in the first group (cluster 1) and 175 were classified in the second group (cluster 2), as shown in Table 4.

Females $\left(\chi_{(1)}^{2}=10.04, P<0.01\right)$, those who had gone beyond primary schooling $\left(\chi_{(1)}^{2}=36.12, P<0.001\right)$, and those whose income was derived from work $\left(\chi_{(1)}^{2}=19.5\right.$, $P<0.001)$ were more likely to be included in cluster 1 . None of the subjects in cluster 1 had used the parenteral route of opioid administration $\left(\chi_{(1)}^{2}=236.18, P<0001\right)$, been diagnosed with HIV/AIDS $\left(\chi_{(1)}^{2}=33.04, P<0.001\right)$ or HCV $\left(\chi_{(1)}^{2}=208.72, P<0.001\right)$, or spent time in prison $\left(\chi_{(1)}^{2}=\right.$ 660.46, $P<0.001)$.

After defining the clusters in the sample of those under the age of 30 years, we analyzed their relationship with the same variables we used in the overall sample (Table 5). Subjects in cluster 2 were younger when they started using opioids than those in cluster $1\left(t_{(646)}=6.03, P<0.001\right)$, had been using for longer $\left(t_{(646)}=-6.76, P<0.001\right)$, were more likely to have used cocaine $\left(\chi_{(1)}^{2}=6.76, P<0.001\right)$, and were less likely to have used it on a daily basis in the previous month $\left(\chi_{(1)}^{2}=6.65, P<0.01\right)$.

Of the 1,007 study participants aged 30 years or older, 543 were classified in the first group (cluster 1) and 464 were 
Table 2 Typologies of users with continuous and categorical variables $(n=I, 655)$

\begin{tabular}{|c|c|c|c|c|c|}
\hline Variables & $\begin{array}{l}\text { Cluster I } \\
n=563\end{array}$ & $\begin{array}{l}\text { Cluster } 2 \\
\mathrm{n}=268\end{array}$ & $\begin{array}{l}\text { Cluster } 3 \\
\mathrm{n}=\mathbf{5 4 0}\end{array}$ & $\begin{array}{l}\text { Cluster } 4 \\
\mathrm{n}=284\end{array}$ & $F / \chi^{2}$ \\
\hline Age, years (SD) & $30.3(7)$ & $37.7(8.2)$ & 35.7 (7.9) & $30.2(8.1)$ & $90.64 * * *, \mathrm{a}$ \\
\hline \multicolumn{6}{|l|}{ Sex, \% } \\
\hline Male & 100 & 100 & 96.9 & 0 & $\mathrm{I}, 544.34 * * *, \mathrm{~b}$ \\
\hline Female & 0 & 0 & 3.1 & 100 & \\
\hline \multicolumn{6}{|l|}{ Marital status, \% } \\
\hline Single & 100 & 0 & 78.1 & 72.2 & $925.63 * * *, c$ \\
\hline Married & 0 & 52.2 & 9.3 & 11.6 & \\
\hline Other & 0 & 47.8 & 12.6 & 16.2 & \\
\hline \multicolumn{6}{|l|}{ Education, \% } \\
\hline Primary & 37.1 & 46.6 & 49.4 & 30.3 & $36.12^{* * *, d}$ \\
\hline Beyond primary & 62.9 & 53.4 & 50.6 & 69.7 & \\
\hline \multicolumn{6}{|l|}{ Source of income, \% } \\
\hline Job & 49.4 & 52.6 & 27.8 & 28.5 & $87.78 * * *, \mathrm{e}$ \\
\hline Other & 50.6 & 47.4 & 72.2 & 71.5 & \\
\hline Intravenous use, \% & 0 & 0 & 41.5 & 12 & $43 I .4 I^{* * *, f}$ \\
\hline HIV/AIDS, \% & 0 & 0 & 21.3 & 2.8 & $226.38 * * * . g$ \\
\hline $\mathrm{HCV}, \%$ & 0 & 0 & 55.4 & 10.6 & $648.72^{* * *, h}$ \\
\hline Incarceration, \% & 0 & 25.4 & 65.4 & 8.8 & $660.46^{* * *, i}$ \\
\hline
\end{tabular}

Notes: ${ }^{* * *} P<0.001$. aBonferroni correction, significant differences between clusters I and 2, I and 3, 2 and 3, 2 and 4, 3 and 4; ${ }^{\mathrm{b} B o n f e r r o n i}$ correction, significant differences between clusters $I$ and $3, I$ and 4, 2 and 3, 2 and 4, 3 and 4 ; 'Bonferroni correction, significant differences between clusters $I$ and $2, I$ and $3, I$ and 4,2 and 3,2 and 4 ,

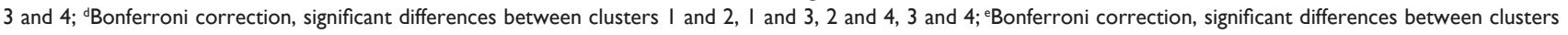

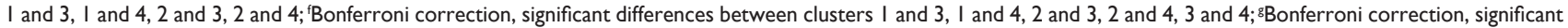
differences between clusters I and 3, I and 4, 2 and 3, 2 and 4, 3 and 4; 'Bonferroni correction, significant differences between clusters I and 3, I and 4, 2 and 3, 2 and 4, 3 and 4; 'Bonferroni correction, significant differences between clusters I and 2, I and 3, I and 4, 2 and 3, 2 and 4, 3 and 4.

Abbreviations: AIDS, acquired immune deficiency syndrome; HCV, hepatitis C virus; HIV, human immunodeficiency virus; SD, standard deviation.

classified in the second group (cluster 2) (Table 6). Those who had completed education beyond primary $\operatorname{school}\left(\chi_{(1)}^{2}=\right.$ $30.66, P<0.001)$ and those whose source of income was from work $\left(\chi_{(1)}^{2}=138.17, P<0.001\right)$ were in cluster 1 . None of the subjects in cluster 1 had used the parenteral route of administration $\left(\chi_{(1)}^{2}=258.23, P<0.001\right)$ or been diagnosed with HIV/AIDS $\left(\chi_{(1)}^{2}=145.99, P<0.001\right)$. They were less likely to have contracted $\operatorname{HCV}\left(\chi_{(1)}^{2}=197.15, P<0.001\right)$, and none had been incarcerated $\left(\chi_{(1)}^{2}=619.57, P<0.001\right)$.
Having defined the clusters in the sample for those aged 30 years or older, we then analyzed their relationship with the same variables used for the overall sample (Table 7). Subjects in cluster 1 were older at age of initiation of use than those in cluster $2\left(t_{(1005)}=6.16, P<0.001\right)$, had been using for fewer years $\left(t_{(1005)}=-9.82, P<0.001\right)$, were less likely to have received psychiatric treatment $\left(\chi_{(1)}^{2}=5\right.$, $P<0.01$ ), were more likely to have sought treatment on their own initiative $\left(\chi_{(1)}^{2}=21.89, P<0.001\right)$, and were more

Table 3 Relationship between typologies of users and other variables associated with opioid addiction $(n=I, 655)$

\begin{tabular}{|c|c|c|c|c|c|}
\hline Variables & $\begin{array}{l}\text { Cluster I } \\
n=563\end{array}$ & $\begin{array}{l}\text { Cluster } 2 \\
n=268\end{array}$ & $\begin{array}{l}\text { Cluster } 3 \\
n=540\end{array}$ & $\begin{array}{l}\text { Cluster } 4 \\
\mathrm{n}=\mathbf{2 8 4}\end{array}$ & $F / \chi^{2}$ \\
\hline Age at initiation of use, years (SD) & $22.2(6.4)$ & $26.1(9.3)$ & $20.2(6.8)$ & $24(7.4)$ & $43.23 * * *, a$ \\
\hline Years of use (SD) & $8.2(8)$ & II $.5(8.5)$ & $15.7(9.4)$ & $6.2(6.1)$ & $\mathrm{I} 10.28 * * *, \mathrm{a}$ \\
\hline Psychiatric treatment (yes) & $19.0 \%$ & $17.5 \%$ & $27.4 \%$ & $35.2 \%$ & $36.46 * * *, b$ \\
\hline Cocaine use (yes) & $53.6 \%$ & $38.8 \%$ & $50.0 \%$ & $53.9 \%$ & $18.1 \mid * * *, c$ \\
\hline Drug-dependent partner (yes) & $21.5 \%$ & $33.8 \%$ & $26.3 \%$ & $53.9 \%$ & $80.31 * * *, d$ \\
\hline \multicolumn{6}{|l|}{ Source of referral } \\
\hline Health services & $16.2 \%$ & $17.9 \%$ & $21.9 \%$ & $20.4 \%$ & $18.68 * *, \mathrm{e}$ \\
\hline Own initiative & $46.5 \%$ & $51.9 \%$ & $38.1 \%$ & $43 \%$ & \\
\hline Other & $37.3 \%$ & $30.2 \%$ & $40 \%$ & $36.6 \%$ & \\
\hline Frequency of daily use in previous month & $77.8 \%$ & $73.9 \%$ & $58 \%$ & $71.5 \%$ & $55.24 * * *, f$ \\
\hline
\end{tabular}

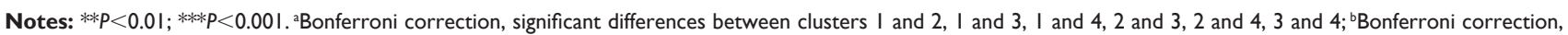
significant differences between clusters I and 3, I and 4, 2 and 3, 2 and 4, 3 and 4; 'Bonferroni correction, significant differences between clusters I and 2, 2 and 3, 2 and 4; 'Bonferroni correction, significant differences between clusters I and 4, 2 and 4, 3 and 4; 'Bonferroni correction, significant differences between clusters I and 3, 2 and 3; 'Bonferroni correction, significant differences between clusters $I$ and 3, I and 4, 2 and 3, 3 and 4.

Abbreviation: SD, standard deviation. 
Table 4 Typologies in users under 30 years of age $(n=648)$

\begin{tabular}{llll}
\hline Variables & $\begin{array}{l}\text { Cluster I } \\
\mathbf{n}=\mathbf{4 7 3}\end{array}$ & $\begin{array}{l}\text { Cluster } \mathbf{2} \\
\mathbf{n}=\mathbf{I 7 5}\end{array}$ & $\chi^{2}$ \\
\hline $\begin{array}{l}\text { Sex, \% } \\
\quad \text { Male }\end{array}$ & 71.9 & 84 & $10.04^{* *}$ \\
$\quad$ Female & 28.1 & 16 & \\
Marital status, \% & & & \\
$\quad$ Single & 88.2 & 87.4 & 0.1 \\
$\quad$ Married & 7.8 & 8 & \\
$\quad$ Other & 4 & 4.6 & \\
Education, \% & & & \\
$\quad$ Primary & 37.1 & 46.6 & $36.12^{* * *}$ \\
$\quad$ Beyond primary & 62.9 & 53.4 & \\
Source of income, \% & & & $19.5 * * *$ \\
$\quad$ Job & 39.7 & 21.1 & \\
$\quad$ Other & 60.3 & 78.9 & $236.18^{* * *}$ \\
Intravenous use, \% & 0 & 44 & $33.04^{* * *}$ \\
HIVIAIDS, \% & 0 & 6.9 & $208.72^{* * *}$ \\
HCV, \% & 0 & 39.4 & $660.46 * * *$ \\
Incarceration, \% & 0 & 56.6 &
\end{tabular}

Notes: **p<0.01; ***p<0.001.

Abbreviations: AIDS, acquired immune deficiency syndrome; $\mathrm{HCV}$, hepatitis $\mathrm{C}$ virus; HIV, human immunodeficiency virus.

likely to have used on a daily basis in the previous month $\left(\chi_{(1)}^{2}=40.98, P<0.001\right)$.

\section{Discussion}

This analysis yielded four clusters of opioid users seeking treatment for the first time, consistent with the initial hypothesis. Earlier age of initiation and more years of use correlated with a greater likelihood of incarceration, more use of the parenteral route of administration, and therefore a greater likelihood of HIV and HCV infection.

What conclusions can we draw from the analysis of these clusters in relation to the variables discussed in the introduction?

\section{Age}

The initial cluster analysis did not yield any conclusive results. The cluster containing the youngest male patients, ie, cluster 1 , had the least clinically and socially severe characteristics, but the mean age in the female cluster was slightly younger and this cluster showed the greater severity. On the other hand, cluster 3 was worst clinically, but subjects in this cluster had a lower mean age than those in cluster 2 , which was of intermediate severity. Undoubtedly, lower age at initiation of use is associated with lower mean age. This is clearly seen in the male clusters, where a more precocious age at initiation resulted in a longer duration of use and increased severity of addiction. In contrast with another study, ${ }^{16}$ we did not find a significant delay in age at initiation in our youngest patients. In the case of the female cluster, ie, cluster 4 , this did not apply, suggesting that women tend to seek treatment earlier than men. Subanalysis of clusters aged younger versus older than 30 years identified two clusters in the under-30 patients, firstly a cluster (73\%) with no history of parenteral drug use, HCV/HIV infection, or prison stays, and secondly another cluster, in which $56.6 \%$ had been incarcerated, $44 \%$ had used the parenteral route of administration, $39.4 \%$ were HCV-positive, and 6.9\% were HIV-positive. This cluster was characterized by greater addiction severity, despite its profile being better than that for subjects aged 30 years or older. In the 30 years or older clusters we see that $53.9 \%$ fell into a cluster in which $0 \%$ had been incarcerated, $0 \%$ used the parenteral route of administration, and $0 \%$ were HIV-positive, with $7.9 \%$ being HCV-positive, compared with $46.1 \%$ that came under another cluster in which $56.6 \%$ had been incarcerated, 39\% had used the parenteral route of administration, $46.8 \%$ were $\mathrm{HCV}$-positive, and $23.9 \%$ were HIV-positive. Women were more represented in the cluster

Table 5 Relationship between typologies of users under 30 years of age and other variables associated with opioid addiction ( $\mathrm{n}=648$ )

\begin{tabular}{|c|c|c|c|}
\hline Variables & $\begin{array}{l}\text { Cluster I } \\
n=473\end{array}$ & $\begin{array}{l}\text { Cluster } 2 \\
n=175\end{array}$ & $t / \chi^{2}$ \\
\hline Age at initiation of use, years (SD) & $20.14(4.58)$ & $17.75(4.13)$ & $6.03 * * *$ \\
\hline Years of use (SD) & $4.78(5.94)$ & $8.13(4.53)$ & $-6.76 * * *$ \\
\hline Psychiatric treatment (yes) & $22.6 \%$ & $26.3 \%$ & 0.95 \\
\hline Use of cocaine (yes) & $54.3 \%$ & $65.7 \%$ & $6.76 * *$ \\
\hline Drug-dependent partner (yes) & $25.2 \%$ & $20 \%$ & 1.87 \\
\hline \multicolumn{4}{|l|}{ Source of referral } \\
\hline Health services & $14.4 \%$ & $17.1 \%$ & 1.24 \\
\hline Own initiative & $40.8 \%$ & $42.3 \%$ & \\
\hline Other & $44.8 \%$ & $40.6 \%$ & \\
\hline Frequency of use in previous month (daily) & $78.9 \%$ & $69.1 \%$ & $6.65 * *$ \\
\hline
\end{tabular}

Notes: $* * P<0.01 ; * * * P<0.001$.

Abbreviation: SD, standard deviation. 
Table 6 Typologies of users aged 30 years or over $(n=I, 007)$

\begin{tabular}{llll}
\hline Variables & $\begin{array}{l}\text { Cluster I } \\
\mathbf{n}=\mathbf{5 4 3}\end{array}$ & $\begin{array}{l}\text { Cluster } \mathbf{2} \\
\mathbf{n}=\mathbf{4 6 4}\end{array}$ & $\chi^{2}$ \\
\hline Sex & & & \\
$\quad$ Male & $84.9 \%$ & $87.5 \%$ & 1.41 \\
$\quad$ Female & $15.1 \%$ & $12.5 \%$ & \\
Marital status & & & \\
$\quad$ Single & $60.4 \%$ & $62.9 \%$ & 1.5 \\
$\quad$ Married & $18.4 \%$ & $15.5 \%$ & \\
$\quad$ Other & $21.2 \%$ & $21.6 \%$ & \\
Education & & & \\
$\quad$ Primary & $32.6 \%$ & $49.8 \%$ & $30.66 * * *$ \\
$\quad$ Beyond primary & $67.4 \%$ & $50.2 \%$ & \\
Source of income & & & \\
$\quad$ Job & $59.1 \%$ & $22.4 \%$ & $138.17^{* * * *}$ \\
$\quad$ Other & $40.9 \%$ & $77.6 \%$ & \\
Intravenous use & $0 \%$ & $39 \%$ & $258.23 * * *$ \\
HIV/AIDS & $0 \%$ & $23.9 \%$ & $145.99 * * *$ \\
HCV & $7.9 \%$ & $46.8 \%$ & $197.15^{* * *}$ \\
Incarceration & $0 \%$ & $56.6 \%$ & $619.57^{* * *}$ \\
\hline
\end{tabular}

Note: $* * * p<0.001$.

Abbreviations: AIDS, acquired immune deficiency syndrome; $\mathrm{HCV}$, hepatitis $\mathrm{C}$ virus; $\mathrm{HIV}$, human immunodeficiency virus.

of patients under 30 years of age and had less clinically severe addiction.

\section{Sex}

As previously shown, women, with a lower incidence for this disorder made up an intermediate severity group. It appeared that the women in our study sought treatment earlier and on their own initiative, were more likely to undergo psychiatric treatment, and were more likely to have a drug-addicted partner. Our results are very similar to those reported elsewhere. ${ }^{3,29}$ Rates of opioid use, history of incarceration, and HIV/HVC status were lower in the female cluster than in the males making up cluster 3 (the most severe group), but were significantly higher in relation to the other male clusters, except for incarceration, rates of which were higher in cluster 2. These data reinforce this intermediate status. It should be noted that the small number of females included in cluster 3 had a high rate of HIV and HCV infection, were more likely to have a drug-addicted partner, were less likely to be single, and had a briefer history of daily use of opioids prior to the start of treatment than males in the same cluster.

The results of our study indicate that women in cluster 4 sought treatment earlier, which would prevent the deterioration seen in the small group in cluster 3, and this pattern has been reported elsewhere. ${ }^{30,31}$

\section{Psychiatric comorbidity}

A previous history of psychiatric treatment was considered an indicator of psychiatric comorbidity, and was clearly higher in females; this was also common in males in cluster 3 , ie, those with the most clinically severe opioid addiction. This would indirectly confirm an increased presence of psychiatric disorders in the most severe cases in both males and females, as other studies that have analyzed female samples in the same time frame have reported. ${ }^{30-32}$

\section{Infectious comorbidity}

The more frequent the use of the parenteral route of administration, the higher the likelihood of contracting HIV and/or $\mathrm{HCV}$ infection. These three variables are decisive for cluster formation, with greater presence in that of greatest clinical severity, cluster 3 .

\section{Legal problems}

In terms of having a history of legal problems, the results are conclusive. Incarceration correlated with years of drug use, this being a clear indicator of addiction severity.

Table 7 Relationship between typologies of users aged 30 years or over and other variables associated with opioid addiction ( $\mathrm{n}=\mathrm{I}, 007)$

\begin{tabular}{|c|c|c|c|}
\hline Variables & $\begin{array}{l}\text { Cluster I } \\
\mathrm{n}=\mathbf{5 4 3}\end{array}$ & $\begin{array}{l}\text { Cluster } 2 \\
n=464\end{array}$ & $t / \chi^{2}$ \\
\hline Age at initiation of use, years (SD) & $25.9(8.1)$ & $22.7(8.3)$ & $6.16 * * *$ \\
\hline Years of use (SD) & II.7 (8.1) & I7.2 (9.6) & $-9.82 * * *$ \\
\hline Psychiatric treatment (yes) & $21.9 \%$ & $28 \%$ & $5 * *$ \\
\hline Cocaine use (yes) & $44.6 \%$ & $46.3 \%$ & 0.31 \\
\hline Drug-dependent partner (yes) & $16.6 \%$ & $17.2 \%$ & 0.07 \\
\hline \multicolumn{4}{|l|}{ Source of referral } \\
\hline Health services & $18.8 \%$ & $24.8 \%$ & $21.89 * * *$ \\
\hline Own initiative & $52.7 \%$ & $37.9 \%$ & \\
\hline Other & $28.5 \%$ & $37.3 \%$ & \\
\hline Frequency of daily use in the last month & $74.2 \%$ & $55 \%$ & $40.98 * * *$ \\
\hline
\end{tabular}

Notes: $* * P<0.01 ; * * * P<0.00$

Abbreviation: SD, standard deviation. 


\section{Marital status}

There has been an increase in the mean age of marriage in Galicia, which makes interpretation of this variable difficult. According to the Spanish Institute for Statistics, ${ }^{33}$ of the total number of marriages recorded in 2013 in Galicia, only $17.96 \%$ involved males under 30 years of age, whereas this figure increased by $30 \%$ in females. It is therefore not surprising that singles predominated in our youngest clusters, ie, clusters 1 and 4. It is indeed relevant that the most severe cluster, ie, cluster 3 , contained a greater proportion of singles when compared with cluster 2 , which had a similar mean age. This finding could indicate a protective factor in this group, or might indicate milder evolution of addiction.

\section{Source of income}

As with marital status, there were more active workers in cluster 2 than in cluster 3 , which is significant and might indicate a protective factor or milder evolution of addiction.

\section{Education}

A higher level of education seemed to correlate more with age than with severity of addiction.

\section{Cocaine use}

Use of cocaine in this study was taken as an indicator of polysubstance abuse. Use of cocaine was high in every cluster, reflecting a high prevalence of cocaine use among current heroin users, as reported in the COPSIAD study, ${ }^{13}$ where $43.1 \%$ of users who reported heroin as their main substance of abuse also used cocaine. These figures are similar to those in the clusters in our study, with the exception of the lower figures in cluster 2 , which contained more chronic users, who were likely to have started using heroin following a more classical, single-substance pattern.

\section{Having a drug-dependent partner}

The likelihood of having a drug-dependent partner was particularly high in the female cluster, which might indicate a more partner-related start and continuation of opioid use.

\section{Frequency of daily opioid use in the previous 30 days}

The high number of subjects who reported using opioids daily in the previous month is to be expected, given that these patients were seeking treatment for the first time. Of particular interest is the fact the cluster with the greatest addiction severity showed the lowest rate of daily opioid use. This could be a consequence of lower socioeconomic status or might reflect a better knowledge of alternative substances available on the black market (methadone and other morphine derivatives or benzodiazepines) that can circumvent the need for daily use of opioids. Alternatively, it might indicate a tendency for opioid use to be minimized in this group. Another explanation is that this early abstinence is related to higher motivation to start treatment. ${ }^{34}$

\section{Study limitations}

The main limitation of this study is that the study sample was collected from different units. While there were common action and collection protocols, and all units were trained in data collection procedures, our data did not have interexaminer reliability. This clinical scenario could have a greater effect on variables that are neither dichotomous nor biological. This group of patients were contacting the Galician addictive disorder treatment network for the first time, but whether they had had previous contact with other public facilities (correctional centers, other Spanish health services) or private services is unknown. This problem has been reported in other epidemiological studies. ${ }^{29}$ Subjects in our study were opioid addicts, and the validity of the data collected has to be considered in light of this fact; nonetheless, this is an important consideration in all studies of this type. ${ }^{35,36}$

However, despite these limitations, this is an extensive group of patients that reflects the real evolution of the demand for treatment resulting from opioid use. Our cluster analysis suggests that duration of use, parenteral drug use with the resulting risk of $\mathrm{HIV} / \mathrm{HCV}$ infection, incarceration, lack of remunerated employment, a history of psychiatric treatment, and being single are associated with greater addiction severity. Women appear to seek help earlier, which reduces their duration of use and improves the initial prognosis. The younger the patient, the briefer the duration of use, the less the likelihood of parenteral drug use, and hence the better the outlook.

\section{Conclusion}

In summary, analysis of clusters in patients seeking treatment for opioid dependency for the first time at the Galician addictive disorder treatment network has given us the opportunity to gain an understanding of their characteristics and typologies, so that interventions can be adapted for this group. Patients presenting with characteristics indicating more severe addiction will require longer maintenance and replacement psychopharmacological treatment, as well as and longer and more intensive psychotherapeutic interventions. 
Patients not presenting with these characteristics could benefit from shorter interventions focused on detoxification/ cessation and occupational recovery.

\section{Acknowledgments}

This study was partly supported by the Instituto de Salud Carlos III, Centro de Investigacion Biomedica en Red de Salud Mental. The authors wish to thank the Galician Health Service for its assistance in preparing this manuscript.

\section{Author contributions}

GF participated in the study design, performed data interpretation, and drafted the manuscript. ALD participated in the study design, performed the statistical analysis, and drafted the manuscript. YT, JO, JF, and JMF participated in the study design and carried out data acquisition and drafted the manuscript. EB participated in the study design, performed the statistical analysis, and critically reviewed and drafted the manuscript. MA participated in the study design, performed data interpretation, and drafted the manuscript. All authors read and approved the final paper and agree to be accountable for all aspects of the work in ensuring that questions related to the accuracy or integrity of any part of the work are appropriately investigated and resolved.

\section{Disclosure}

The authors report no conflicts of interest in this work.

\section{References}

1. Bobes García J, Bobes Bascarán MT. [Long term effectiveness of methadone maintenance treatments in persons with addiction to opiates]. Adicciones. 2012;24:179-183. Spanish.

2. Day E, Ison J, Strang J. Inpatient versus other settings for detoxification for opioid dependence. Cochrane Database Syst Rev. 2005;(2): CD004580.

3. European Monitoring Centre for Drugs and Drug Addiction. European Drug Report: Trends and Developments 2014. Luxembourg: Publications Office of the European Union; 2014. Available from: http://www. emcdda.europa.eu/publications/edr/trends-developments/2014. Accessed March 7, 2015.

4. Chesney E, Goodwin GM, Fazel S. Risks of all-cause and suicide mortality in mental disorders: a meta-review. World Psychiatry. 2014;13: 153-160.

5. Spanish Observatory of Drugs and Drug Addiction. Observatorio Español sobre drogas, informe 2011 [Spanish Monitoring Centre for Drugs and Drug Addiction Report 2011]. Madrid: Ministry of Health, Social Policy and Equality; 2011. Availbale from: http://www.pnsd.msssi. gob.es/Categoria2/publica/pdf/oed2011.pdf. Accessed Jan 20,2012. Spanish.

6. Regional Health Authority. Plan de Trastornos Adictivos de Galicia 2011-2016 [Plan for Addictive Disorders of Galicia 2011-2016]. Santiago de Compostela: Ministry of Health; 2011. Spanish.

7. Landreat MG, Vigneau CV, Bronnec MG, Sebille-Rivain V, Venisse JL, Jolliet P. [Description of medicosocial profiles of pharmacodependent subjects consulting addictology centres using a computerized database]. Encephale. 2011;37:418-424. French.
8. del Río EF, Becoña E, Durán AL. Subtypes of smokers who attend psychological treatment in order to stop smoking. Subst Use Misuse. 2011;46:1113-1123.

9. Carpenter KM, Liu X, Hasin DS. The Type A-Type B classification in a community sample of problem drinkers: structural and predictive validity. Addict Behav. 2006;31:15-30.

10. López Durán A, Becoña Iglesias E. Subtyping of individuals undergoing treatment for cocaine dependence. Psicothema. 2008;20:538-544.

11. Chiang SC, Chan HY, Chang YY, Sun HJ, Chen WJ, Chen CK. Psychiatric comorbidity and gender difference among treatment-seeking heroin abusers in Taiwan. Psychiatry Clin Neurosci. 2007;61:105-111.

12. Mateu G, Astals M, Torrens M. Comorbilidad psiquiátrica y trastorno por dependencia de opiáceos: del diagnóstico al tratamiento [Psychiatric comorbidity and opioid dependence disorder: from diagnosis to treatment]. Adicciones. 2005;17:111-121. Spanish.

13. Pereiro C, Pino C, Flórez G, Arrojo M, Becoña E; COPSIAD Group. Psychiatric comorbidity in patients from the Addictive Disorders Assistance Units of Galicia: the COPSIAD Study. PLoS One. 2013;8: e66451.

14. Soyka M, Kranzler HR, van den Brink W, Krystal J, Möller HJ, Kasper S; Task Force on Treatment, Guidelines for Substance Use Disorders. The World Federation of Societies of Biological Psychiatry (WFSBP) guidelines for the biological treatment of substance use and related disorders. Part 2: opioid dependence. World J Biol Psychiatry. 2011; 12:160-187.

15. Fattore L, Altea S, Fratta W. Sex differences in drug addiction: a review of animal and human studies. Womens Health (Lond Engl). 2008;4:51-65.

16. Grella CE, Lovinger K. Gender differences in physical and mental health outcomes among an aging cohort of individuals with a history of heroin dependence. Addict Behav. 2012;37:306-312.

17. European Monitoring Centre for Drugs and Drug Addiction. Annual Report 2006: Selected Issues. Luxembourg: Office for Official Publications of the European Communities; 2006. Available from: http:// www.drugs.ie/resourcesfiles/ResearchDocs/Europe/Research/2006/ sel2006_2-en.pdf. Accessed March 7, 2015.

18. Domingo-Salvany A, Brugal MT, Barrio G, González-Saiz F, Bravo MJ, de la Fuente L; ITINERE Investigators. Gender differences in health related quality of life of young heroin users. Health Qual Life Outcomes. 2010;8:145.

19. Maremmani I, Pani PP, Pacini M, et al. Subtyping patients with heroin addiction at treatment entry: factor derived from the Self-Report Symptom Inventory (SCL-90). Ann Gen Psychiatry. 2010;9:15.

20. Jimenez-Treviño L, Saiz PA, García-Portilla MP, et al. A 25-year follow-up of patients admitted to methadone treatment for the first time: mortality and gender differences. Addict Behav. 2011;36:1184-1190.

21. National Institute for Health and Care Excellence (NICE). Methadone and Buprenorphine for the Management of Opioid Dependence. London: National Institute for Health and Clinical Excellence; 2007. Available from: http://www.nice.org.uk/guidance/ta114. Accessed March 7, 2015.

22. Chang KC, Loh el-W, Tang HP, et al. Disparity between heroin addicts enrolled in maintenance treatment and detoxification treatment and its implication. Asian J Psychiatr. 2010;3:138-141.

23. Wu LT, Ling W, Burchett B, Blazer DG, Shostak J, Woody GE. Gender and racial/ethnic differences in addiction severity, HIV risk, and quality of life among adults in opioid detoxification: results from the National Drug Abuse Treatment Clinical Trials Network. Subst Abuse Rehabil. 2010; 2010(1):13-22.

24. Cicero TJ, Ellis MS, Surratt LS, Kurtz SP. The changing face of heroin use in the United States: a retrospective analysis of the past 50 years. JAMA Psychiatry. 2014;71:821-826.

25. McLellan AT, Luborsky L, Woody GE, O’Brien CP. An improved diagnostic evaluation instrument for substance abuse patients. The Addiction Severity Index. J Nerv Ment Dis. 1980;168:26-33.

26. Milligan GW, Hirtle SC. Clustering and classification methods. In: Schinka JA, Velicer WF, editors. Handbook of Psychology. Volume 2: Research Methods in Psychology. Hoboken: John Wiley \& Sons, Inc; 2003. 
27. Everitt BS, Landau S, Leese M. Cluster Analysis. 4th ed. New York: Oxford University Press; 2001.

28. Li W, Nyholt DR. Marker selection by Akaike information criterion and Bayesian information criterion. Genet Epidemiol. 2001;21 Suppl 1: S272-S277.

29. Substance Abuse and Mental Health Services Administration, Center for Behavioral Health Statistics and Quality. Treatment Episode Data Set (TEDS): 2002-2012. National Admissions to Substance Abuse Treatment Services. BHSIS Series S-71, HHS Publication No. (SMA) 14-4850. Rockville, MD: Substance Abuse and Mental Health Services Administration; 2014. Available from: http://www.samhsa.gov/data/ sites/default/files/TEDS2012N_Web.pdf. Accessed March 7, 2015.

30. Anker JJ, Carroll ME. Females are more vulnerable to drug abuse than males: evidence from preclinical studies and the role of ovarian hormones. Curr Top Behav Neurosci. 2011;8:73-96.

31. Back SE, Payne RL, Wahlquist AH, et al. Comparative profiles of men and women with opioid dependence: results from a national multisite effectiveness trial. Am J Drug Alcohol Abuse. 2011;37:313-323.
32. Sordo L, Chahua M, Bravo MJ, et al; ITINERE Project Group. Depression among regular heroin users: the influence of gender. Addict Behav. 2012:37:148-152.

33. Fenómenos demográficos. Movimiento Natural de la Población [Demographic phenomena. Vital Statistics] [webpage on the Internet]. Madrid: Instituto Nacional de Estadística; 2014. Available from: http://www. ine.es/jaxi/menu.do?type $=$ pcaxis \&path $=\% 2 \mathrm{Ft} 20 \% 2 \mathrm{Fe} 302 \&$ file $=$ ineba se $\&$ L $=0$. Accessed April 16, 2014. Spanish, English.

34. Cochran G, Stitzer M, Nunes EV, Hu MC, Campbell A. Clinically relevant characteristics associated with early treatment drug use versus abstinence. Addict Sci Clin Pract. 2014;9:6.

35. Shaw SY, Shah L, Jolly AM, Wylie JL. Identifying heterogeneity among injection drug users: a cluster analysis approach. Am J Public Health. 2008;98:1430-1437.

36. Schönnesson LN, Atkinson J, Williams ML, Bowen A, Ross MW, Timpson SC. A cluster analysis of drug use and sexual HIV risks and their correlates in a sample of African-American crack cocaine smokers with HIV infection. Drug Alcohol Depend. 2008;97:44-53.

\section{Publish your work in this journal}

Neuropsychiatric Disease and Treatment is an international, peerreviewed journal of clinical therapeutics and pharmacology focusing on concise rapid reporting of clinical or pre-clinical studies on a range of neuropsychiatric and neurological disorders. This journal is indexed on PubMed Central, the 'PsycINFO' database and CAS,

\section{Dovepress}

and is the official journal of The International Neuropsychiatric Association (INA). The manuscript management system is completely online and includes a very quick and fair peer-review system, which is all easy to use. Visit http://www.dovepress.com/testimonials.php to read real quotes from published authors. 